\title{
Optimized and scaled-up production of cellulose-reinforced biodegradable composite films made up of carrot processing waste
}

\author{
Caio G. Otoni ${ }^{\mathrm{a}, \mathrm{b}, *}$, Beatriz D. Lodi ${ }^{\mathrm{a}}$, Marcos V. Lorevice ${ }^{\mathrm{a}}$, Renato C. Leitão ${ }^{\mathrm{c}}$, Marcos D. Ferreira ${ }^{\mathrm{a}}$, \\ Márcia R. de Moura ${ }^{\mathrm{d}}$, Luiz H.C. Mattoso ${ }^{\mathrm{a}}$ \\ ${ }^{a}$ Nanotechnology National Laboratory for Agriculture (LNNA), Embrapa Instrumentation, Rua XV de Novembro, 1452, São Carlos, SP 13560-979, Brazil \\ ${ }^{\mathrm{b}}$ PPG-CEM, Department of Materials Engineering, Federal University of São Carlos, Rod. Washington Luis, km 235, São Carlos, SP 13565-905, Brazil \\ ${ }^{c}$ Embrapa Tropical Agroindustry, Rua Dra. Sara Mesquita 2270, Fortaleza, CE 60511-110, Brazil \\ d Department of Physics and Chemistry, FEIS, São Paulo State University, Av. Brasil, 56, Ilha Solteira, SP, 15385-000, Brazil
}

\section{A R T I C L E I N F O}

\section{Keywords:}

Biopolymer

Cellulose derivative

Biocomposite

Daucus carota L.

Residue

Biodegradability

\begin{abstract}
A B S T R A C T
The ever-growing environmental concern arising from the unrestricted exploitation of fossil sources for the massive production of non-biodegradable materials encourages research on alternative renewable resources. We herein pave the route for the production of biodegradable biocomposites made up of carrot minimal processing waste (CMPW) by optimizing its combination with hydroxypropyl methylcellulose (HPMC) and high-pressure microfluidized cellulose fibers, which played ligand and mechanical reinforcement roles, respectively. Ternary mixture designs established mathematical models aimed at structure-composition-property correlations, allowing their mechanical performances to be innovatively predicted without the need for further experiments. The optimized formulation comprised $33 \mathrm{wt}$ \% CPMW and led to biodegradable biocomposites featuring ca. $30 \mathrm{MPa}$ of tensile strength, $c a$. 3\% elongation at break, and $c a .2 \mathrm{GPa}$ of Young's modulus, properties which are suitable for food packaging applications. Finally, the film-forming protocol was successfully scaled-up through a continuous casting approach, allowing the production of $1.56 \mathrm{~m}^{2}$ of biodegradable biocomposite in each hour. While scaling up did not affect film's barrier to moisture, it did impair its mechanical behavior.
\end{abstract}

\section{Introduction}

Globalization and industrialization are increasingly demanding more complex food distribution systems. This scenario leads to longer transportation and storage periods, during which food products are susceptible to microbial spoilage as well as sensory and nutritional losses, in addition to increased packaging requirements in terms of production and properties. Among properties, the mechanical and water barrier denote the most relevant for commercial food packaging applications (Hosseini et al., 2015; Souza et al., 2017). Polymers obtained through petrochemical routes are traditionally the most exploited due to their advantageous cost-benefit ratios as well as suitable properties (Ferrer et al., 2017). However, the forthcoming limitation of fuel sources and the growing environmental concern regarding the disposal of non-biodegradable materials motivate the use of polymers that are biodegradable and/or obtained from renewable raw materials (Otoni et al., 2017; Souza et al., 2017).

A further environmentally friendly approach of producing bio-based packaging materials without competing with commercial applications (e.g., food versus feed paradigm) relies on the use of underutilized natural resources as well as of the by-products, residues or wastes resulting from their processing operations (Graichen et al., 2017). In this context, researchers have been taking advantage of overripe fruit and vegetable processing waste to produce edible and/or biodegradable bioplastics (Andrade et al., 2016; de Moraes Crizel et al., 2016; Otoni et al., 2017). This strategy is interesting because it combines the unique sensory and nutritional aspects of such plant materials with their filmforming components. Studies on the formulation of edible and/or biodegradable bioplastics primarily based on underutilized portions of fruits and vegetables are however scarce, making this topic worthy of further exploitation.

Carrot (Daucus carota L.) is a widely grown, non-seasonal vegetable

\footnotetext{
Abbreviations: ANOVA, analysis of variance; CMPW, carrot minimum processing waste; EVOH, ethylene vinyl alcohol copolymer; FFF, film-forming formulation; HDPE, high-density

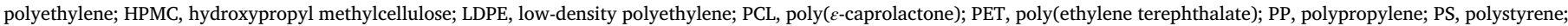
PVC, polyvinylchloride; PVDC, poly(vinylidene chloride); RH, relative humidity; TPS, thermoplastic starch; WVP, water vapor permeability

* Corresponding author at: Nanotechnology National Laboratory for Agriculture (LNNA), Embrapa Instrumentation, Rua XV de Novembro, 1452, São Carlos, SP, 13560-970, Brazil.

E-mail addresses: cgotoni@gmail.com (C.G. Otoni), beatrizdlodi@hotmail.com (B.D. Lodi), marcos.lorevice@gmail.com (M.V. Lorevice), renato.leitao@embrapa.br (R.C. Leitão), marcos.david@embrapa.br (M.D. Ferreira), marcia@dfq.feis.unesp.br (M.R.d. Moura), luiz.mattoso@embrapa.br (L.H.C. Mattoso).
} 
featuring pleasant flavor and rich in phenolic compounds, carotenoids (e.g., $\beta$-carotene), vitamins, minerals, and dietary fiber (Alasalvar et al., 2001; Hiranvarachat and Devahastin, 2014). Approximately 70-75\% of harvested carrots are marketed after minimal processing into Baby Carrots $^{\mathrm{TM}}$, carrot chips and sticks, and chopped, shredded, and sliced carrots (Du et al., 2012). Nevertheless, minimal processing yields are typically low: ca. $40 \%$ of the initial carrot weight is discarded after peeling, shaping, polishing, and sorting (Silva et al., 2008). Carrot minimal processing waste (CMPW), which is often thrown away or used as animal feed (Iahnke et al., 2015), contains high content of organic matter - which implies difficult disposal - and presents great potential of use, mainly due to its nutritional properties.

Iahnke et al. (2015) combined fibers from carrot processing residue with bovine gelatin waste - resulting from the production of linseed oil capsules - to produce films through bench casting. Both components were necessary because, in most cases, the film-forming constituents naturally present in fruits and vegetables are not able to form cohesive layers that are detachable from the casting substrate (Otoni et al., 2017). Several binding agents have been used to create self-standing edible and/or biodegradable bioplastics, including cellulose derivatives, as this raw material is the most abundant biopolymer on earth (Kanmani et al., 2017). Hydroxypropyl methylcellulose (HPMC) is a cellulose ether with widely reported film-forming ability (Otoni et al., 2018). It has been combined with other fruit and vegetable purees to produce bioplastics (Lorevice et al., 2014, 2012).

Even if they are detachable from the casting surface, edible and/or biodegradable films often present poorer mechanical and water barrier properties than those based on petroleum-derived polymers (Otoni et al., 2017), requiring the addition of another component to act as a reinforcement filler (Azeredo, 2009). Lignocellulosic fibers have been widely exploited in this context (Azeredo et al., 2017; Ferrer et al., 2017). Cellulose fibers/crystals were previously combined with HPMC (Bilbao-Sáinz et al., 2010; Bilbao-Sainz et al., 2011; de Moura et al., 2011; Dogan and McHugh, 2007; George et al., 2014) or fruit puree (Azeredo et al., 2009; Azeredo et al., 2012). However, to the best of our knowledge, cellulose fibers, HPMC, and fruit/vegetable purees have never been combined into biocomposite films.

In line with the environmental concerns raised above as well as with the trend towards the maximum use of natural resources, this contribution set out to produce biodegradable - the biodegradability was actually determined - biocomposites based on CMPW in combination with HPMC and cellulose fibers. Understanding the role that each component played in the physical-mechanical performances of the resulting materials was another aim of this research in order to allow correlations between structures, compositions, and properties. Ternary mixture design was used to optimize the properties of the biocomposites, which were then scaled up from a laboratory to a pilot scale. Finally, the influence of the film-forming protocols - bench and continuous casting - on their properties was investigated.

\section{Material and methods}

\subsection{Materials}

Freshly harvested carrots (length: $26 \pm 2 \mathrm{~cm}$; diameter: $4.2 \pm 0.6 \mathrm{~cm}$ ) were provided by a local grower in São Carlos, Brazil. HPMC Methocel $^{\circ}$ E4 M [CAS No. 9004-65-3; weight average molecular weight: $c a$. $350,000 \mathrm{~g} \mathrm{~mol}^{-1}$ (Otoni et al., 2018); viscosity ( $2 \%$ dispersion in water, at $0.1 \mathrm{~s}^{-1}$ and $20^{\circ} \mathrm{C}$ ): $c a .4000 \mathrm{mPa} \mathrm{s}^{-1}$ (Otoni et al., 2018); substitution degree: 1.9] was kindly supplied by The Dow Chemical Company (Brazil) and used as received. Microcrystalline cellulose (Sigmacell ${ }^{\circ}$ Type 50 ) was provided by Sigma-Aldrich Brazil Ltda. (Brazil), suspended in deionized water at $1 \%\left(\mathrm{w} \mathrm{v}^{-1}\right)$, and submitted to seven cycles of high-pressure microfluidization (Microfluidizer model M-110P, Microfluidics Corp., USA) at $138 \mathrm{MPa}$, relying upon preliminary experiments (data not shown). Ultrapure, deionized water (Barnstead Nanopure Diamond, USA) was used in all experiments.

\subsection{Carrot minimal processing}

Fresh carrots were minimally processed according to Moretti and Mattoso (2007). First, $100 \mathrm{~mL}$ of a $50 \%$ benzalkonium chloride solution was diluted in $20 \mathrm{~L}$ of water. This solution was used for sanitizing the cold room and food-contacting surfaces and utensils. Carrots were sanitized in $200 \mathrm{ppm}$ sodium hypochlorite solution for $10 \mathrm{~min}$ at $4 \pm 1{ }^{\circ} \mathrm{C}$ and $\mathrm{pH} c a$. 7.5. The tops of the sanitized roots were removed prior to peeling and cutting into $c a$. $1-\mathrm{cm}$-sided cubes. The remainder - tops and other visually impaired portions - were discarded, while the other portions were kept for another $10 \mathrm{~min}$ in the same sanitizing solution before being centrifuged. CMPW - i.e., scrapings and non-uniform pieces that would not be marketed as minimally processed products was freeze-dried and ground into powder in a ball mill.

\subsection{Effect of CMPW on the mechanical and water barrier properties of HPMC films}

\subsubsection{Film production via bench casting}

CMPW and HPMC Methocel ${ }^{\circ}$ E4 M were combined at different weight ratios (Table 1) in water upon mechanical stirring at $1500 \mathrm{rpm}$ for $30 \mathrm{~min}$ under vacuum $(-500 \mathrm{mmHg})$, at $25 \pm 2{ }^{\circ} \mathrm{C}$.

The film-forming formulations (FFF) were allowed to rest under vacuum for another $30 \mathrm{~min}$ before being spread with uniform thickness onto a poly(ethylene terephthalate) (PET) sheet. FFF were allowed to dry on the bench at $25 \pm 2{ }^{\circ} \mathrm{C}$ and $50 \pm 10 \%$ relative humidity (RH) for $24 \mathrm{~h}$. Dried films were peeled from the casting surface and equilibrated at $50 \% \mathrm{RH}$ for $48 \mathrm{~h}$ in a desiccator containing saturated magnesium nitrate solution prior to testing.

\subsubsection{Mechanical properties}

Films samples were shaped into at least six test specimens per treatment according to ASTM D882-12 (ASTM, 2012c) and submitted to uniaxial tensile assay on a universal testing machine (model DL3000, EMIC Equipamentos e Sistemas de Ensaio Ltda., Brazil) equipped with a 10-kgf load cell. Film specimens - initial length $\left(L_{O}\right): 100 \mathrm{~mm}$ - were uniaxially stretched at $10 \mathrm{~mm} \mathrm{~min}^{-1}$ to calculate tensile strength $\left(\sigma_{T}\right)$, Young's modulus $(E)$, and elongation at break $\left(\varepsilon_{B}\right)$ using Eq. (1)-(3), respectively.

$$
\begin{aligned}
\sigma_{T} & =F / A_{0} \\
E & =\lim _{L \rightarrow 0} \sigma / L \\
\varepsilon_{B} & =\left[\left(L-L_{0}\right) / L_{0}\right] \cdot 100
\end{aligned}
$$

Wherein $F$ is the maximum load, $L$ is the ultimate specimen extension prior to breakage, and $A_{0}$ is the initial specimen cross-sectional area. Thickness was previously measured to the nearest $0.001 \mathrm{~mm}$ with a digital micrometer (Mitutoyo Corp., Japan) at three random positions throughout.

\section{Table 1}

Film-forming formulations (FFF). Compositions of aqueous FFF containing different contents of carrot minimal processing waste (CMPW) and hydroxypropyl methylcellulose (HPMC).

\begin{tabular}{llll}
\hline HPMC:CMPW (wt. ratio) & HPMC $(\mathrm{g})$ & CMPW $(\mathrm{g})$ & Water $(\mathrm{mL})$ \\
\hline $1: 0$ & 1.6 & - & 80 \\
$2: 1$ & 1.1 & 0.5 & 80 \\
$1: 1$ & 0.8 & 0.8 & 80 \\
$2: 3$ & 0.6 & 1.0 & 80 \\
$0: 1$ & - & 1.6 & 80 \\
\hline
\end{tabular}


Table 2

Mixture design. Weigh ratios $(X)$ of carrot minimal processing waste (CMPW), cellulose fibers $(C F)$, and hydroxypropyl methylcellulose (HPMC) in $2 \%$ (w $\mathrm{v}^{-1}$ ) film-forming formulations.

\begin{tabular}{llll}
\hline Experiment & $X_{C M P W}$ & $X_{H P M C}$ & $X_{C F}$ \\
\hline 1 & 0.00 & 1.00 & 0.00 \\
2 & 0.20 & 0.40 & 0.40 \\
3 & 0.40 & 0.30 & 0.30 \\
4 & 0.20 & 0.15 & 0.65 \\
5 & 0.00 & 0.50 & 0.50 \\
6 & 0.40 & 0.00 & 0.60 \\
7 & 0.00 & 0.00 & 1.00 \\
8 & 0.40 & 0.60 & 0.00 \\
9 & 0.80 & 0.20 & 0.00 \\
10 & 0.80 & 0.00 & 0.20 \\
11 & 0.00 & 0.50 & 0.50 \\
12 & 0.00 & 0.00 & 1.00 \\
13 & 0.60 & 0.25 & 0.15 \\
14 & 0.20 & 0.65 & 0.15 \\
15 & 0.00 & 1.00 & 0.00 \\
\hline
\end{tabular}

\subsubsection{Water vapor permeability (WVP)}

Films were analyzed with regard to their barriers to water vapor in accordance with a modification of ASTM E96-80 (McHugh et al., 1993). Briefly, samples were fixed to the edges of poly(methyl methacrylate) capsules with circular openings of $50.8 \mathrm{~mm}$ in diameter. The films were used as semi-permeable barriers between the inside of the capsules - containing $6 \mathrm{~mL}$ of water - and a cabinet at $30 \pm 1{ }^{\circ} \mathrm{C}$ and $\mathrm{RH}$ of $30 \pm 2 \%$ (monitored by a portable thermohygrometer and maintained by periodically supplying suitable amounts of dried silica). Test capsules were weighed periodically during $24 \mathrm{~h}$ for WVP determinations. At least four replicates of each treatment were assayed.

\subsection{Optimization of the biocomposites}

Cellulose fibers, CMPW, and HPMC were combined at different proportions by means of a ternary mixture design (Table 2).

The weight ratios of HPMC and cellulose fibers varied from 0 to $100 \%$, whereas that of CMPW was limited to $80 \%$, as preliminary experiments (data not shown) indicated that higher CMPW contents would not lead to cohesive, detachable layers as free-standing films. The films were produced by bench casting as described previously (item 2.3.1) and subjected to tensile assay on a dynamic-mechanical analyzer (model DMA Q800 model, TA Instruments, Inc., USA) equipped with a 18-N load cell. Samples were stretched at $0.1 \% \mathrm{~min}^{-1}$ in accordance with ASTM D882-12 (ASTM, 2012c). The mechanical attributes tensile strength, Young's modulus, and elongation at break were determined (item 2.3.1) and taken as response variables for building response surfaces.

\subsection{Scaling up the optimal biocomposite}

The optimal formulation $\left(X_{C M P W}=0.33, \quad X_{H P M C}=0.14\right.$, $X_{C F}=0.53$-discussed in Section 3.3) was used to produce films through a continuous approach on a lamination system (model KTF-B, Werner Mathis AG, Switzerland). The FFF was poured on a conveyor belt made up of the polyester Mylar (DuPont Teijin Films U.S. Ltd., USA) and evenly spread by a Teflon-coated knife into a 1.50 -mm-thick, $26-\mathrm{cm}$ wide wet layer. The film-forming layer was conveyed at $0.10 \mathrm{~m} \mathrm{~min}^{-1}$ through a pre-drying stage with infrared radiation $\left(30 \mathrm{~cm}\right.$ at $\left.\mathrm{ca} .45^{\circ} \mathrm{C}\right)$ and two convective drying stages $\left(92 \mathrm{~cm}\right.$ each) at $120^{\circ} \mathrm{C}$. Then, the dried material was detached from the substrate and wound. The distance traveled from the feed to the end of the last oven was $3.0 \mathrm{~m}$, which took $30 \mathrm{~min}$ at this speed. The same FFF was used to produce films by bench casting (item 2.3.1) for comparison purposes.

\subsubsection{Aerobic biodegradability in soil}

The behavior of both bench- and continuous-cast biocomposites in soil was evaluated for $75 \mathrm{~d}$ at $30^{\circ} \mathrm{C}$. The carbon dioxide resulting from aerobic biodegradation was quantified on an automatic respirometer (Micro-Oxymax Respirometer System, Columbus Instruments, USA). The aerobic biodegradation assay was performed in accordance with ASTM D5988-12 (ASTM, 2012b), with a few adaptations. A mixture comprising $50 \mathrm{wt} . \%$ (dry basis) of a cattle manure:sugarcane bagasse (1:2) compound and 50 wt.\% (dry basis) of earthworm humus. The inoculum humidity was adjusted to $60 \%$. The biocomposites were milled on an impact mill (model A 11, IKA Works Inc., Germany), sieved through a 50-mesh (300- $\mu \mathrm{m}$ opening) sieve, and vigorously mixed with the inoculum in hermetically sealed, borosilicate glass vessels connected to the respirometer as a closed system. Each vessel was added with $4.95 \mathrm{~g}$ of inoculum and $0.05 \mathrm{~g}$ of sample. Vessels containing $5.00 \mathrm{~g}$ of inoculum were used as a blank, whereas those containing soluble starch P.A. ACS (Dinâmica Química Contemporânea Ltda., Brazil) instead of biocomposites film were used as positive control since it is a widely reported biodegradable material (de Campos et al., 2013; Li et al., 2011). To eliminate the effect of particle size (i.e., powder versus milled film), films made up of starch plasticized with $30 \mathrm{wt} . \%$ glycerol (TPS) were tested likewise, serving as an additional positive control. Each treatment was tested in triplicates, totaling 12 vessels. On a weekly basis, $0.5 \mathrm{~mL}$ of water was added to each vessel for moisture maintenance purposes. To calculate biocomposites' biodegradation through carbon dioxide production (Table 5), theoretical carbohydrate molecules $\left(\mathrm{C}_{\mathrm{X}} \mathrm{H}_{\mathrm{Y}} \mathrm{O}_{\mathrm{Z}}\right)$ were constructed from $\mathrm{C}, \mathrm{H}$, and $\mathrm{O}$ determinations on an elemental analyzer (model 2400 CHNS/O Series II, PerkinElmer Inc., USA).

\subsubsection{Physical-mechanical properties}

The bench- and continuous-cast optimal biocomposites were characterized in terms of their mechanical and water barrier properties, as described in Sections 2.3.2 and 2.3.3, respectively. The mechanical attributes were measured in both parallel and transversal directions to lamination. In addition, the hydrophilic/hydrophobic nature of these materials were studied on an automatic optical goniometer (model CAM 101, KSV Instruments, Finland), which monitored the angle between an ultrapure water drop (5-7 $\mu \mathrm{L})$ and biocomposite surfaces at every $3 \mathrm{~s}$ during $180 \mathrm{~s}$. The mean contact angle at each measurement time was an average of the angles determined at the right and left ends of the drop. Each film was analyzed in at least 7 points.

\subsection{Statistical treatment of the data}

Quantitative data were submitted to analysis of variance (ANOVA) at $5 \%$ of significance followed by regression analysis or Tukey test for mean comparison, as suitable, using Minitab (version 13.31) software (Minitab Inc., USA). Quadratic regression models were adjusted for the mechanical data generated in the mixture design using Statistica (version 8.0) software (StatSoft Inc., USA). The importance of the model components was evaluated by ANOVA and only the significant effects were maintained. The level of significance was $5 \%$ as well.

\section{Results and discussion}

\subsection{Carrot minimal processing}

CMPW represented a substantial part of the minimally processed carrot volume (Table 3 ).

The yield of the minimal processing was similar to that reported by Silva et al. (2008): 40\% of the initial carrot amount was discarded during Baby Carrots ${ }^{\mathrm{TM}}$ production. CMPW retains vitamins, minerals, fibers, and volatiles, the latter being mainly responsible for carrot sensory characteristics. Therefore, CMPW has great potential to be used as a low-cost resource featuring sensory and nutritional qualities, even 
Table 3

Carrot processing efficiency. Yields of each portion obtained in carrot minimal processing

\begin{tabular}{lll}
\hline Portion & Weight $(\mathrm{kg})$ & Yield $\left(\% \mathrm{~m} \mathrm{~m}^{-1}\right)$ \\
\hline Carrot & 5.31 & - \\
Minimally processed carrot & 2.41 & 45.3 \\
Losses & 0.45 & 8.5 \\
Exploitable waste & 2.45 & 46.2
\end{tabular}

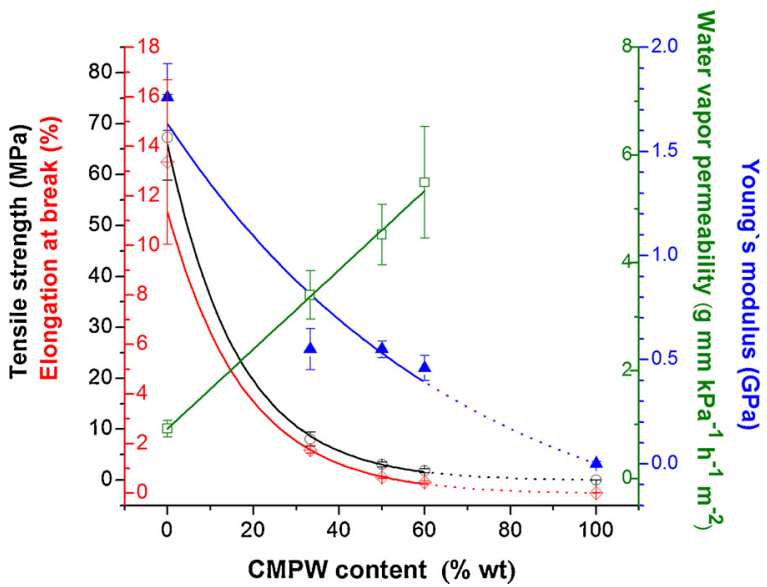

Fig. 1. Mechanical and water barrier properties of CMPW/HPMC films. Mechanical properties: tensile strength (O), elongation at break $(\diamond)$, Young's modulus ( $\mathbf{A})$, and water vapor permeability $(\square)$ of bioplastics comprising different contents of carrot minimal processing waste (CMPW).

for value-added applications. Because minimally processed carrot already holds its market share (Du et al., 2012), and considering the underutilization of CMPW, the scope of this work included the exclusive exploitation of CMPW for producing biodegradable biocomposites.

\subsection{Effect of CMPW on bioplastic properties}

The mechanical attributes and WVP of the bioplastics formulated with different HPMC and CMPW ratios are presented in Fig. 1.

As already mentioned, CMPW alone did not lead to a cohesive, detachable layer, i.e., the film-forming components present in CMPW were not sufficient to form self-standing films. Therefore, HPMC was added as a binding agent. The mechanical and water barrier properties of CMPW/HPMC films were affected by the proportions between the components. More specifically, the WVP $\quad(* \mathrm{P}<0.05$; $\left.W V P=0.923+0.074 \cdot x ; R^{2}=0.999\right)$, tensile strength (*P $<0.05$; $\left.\sigma_{T}=66.06 \cdot e^{(-x / 16.53)}-0.16 ; \quad R^{2}=0.993\right), \quad$ Young's modulus $\left({ }^{*} \mathrm{P}<0.05 ; E=2.13 \cdot e^{(-x / 68.56)}-0.49 ; R^{2}=0.950\right)$ and elongation at break ( $\left.{ }^{*} \mathrm{P}<0.05 ; \varepsilon_{B}=11.38 \cdot e^{(-x / 17.97)}-0.04 ; R^{2}=0.985\right)$ of these materials were as high as the HPMC content. Thus, the addition of this component to the FFF is in line with the technological demand for highly resistant, stiff, extensible, tough, and poorly permeable materials for food packaging applications. CMPW, contrastingly, impaired the mechanical and water barrier performances of HPMC films, acting as macroscopic defects in the polymer matrix. In case of mechanical properties, such defects behave as tension concentrator points upon tensile request, anticipating specimen failure. WVP, in turn, indicates the ability of a material in allowing the diffusion of water molecules. Although HPMC is predominantly hydrophilic, high contents of this component provided films with lower WVP values due to the formation of a compact matrix with a lower occurrence of defects capable of facilitating the diffusional process. These observations justify the need for a reinforcing agent to produce CMPW-based biocomposites with suitable physical-mechanical properties for commercial applications as packaging materials.
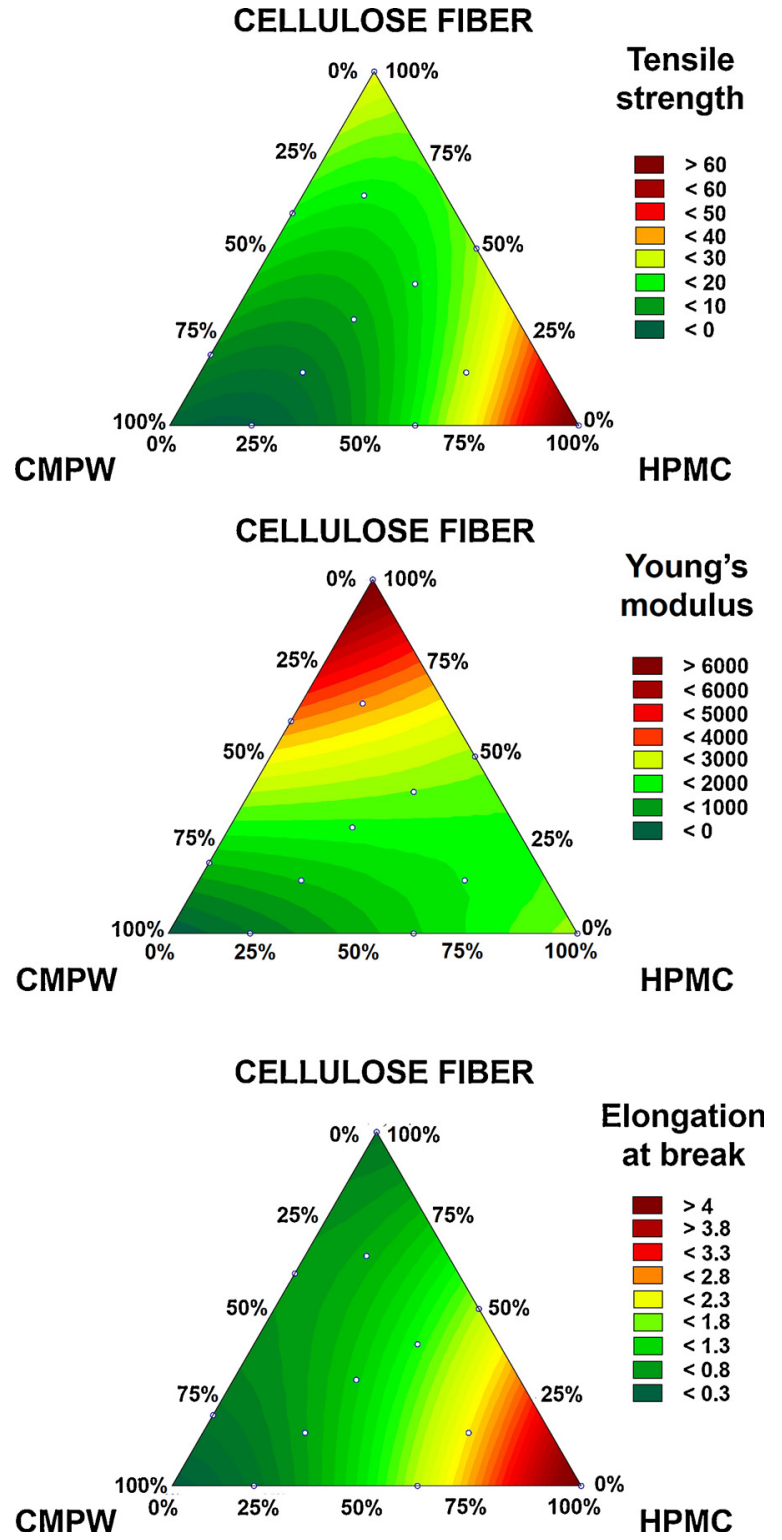

Fig. 2. Ternary mixture experiments of biocomposites. Mechanical properties of biocomposites made up of different weight rations of hydroxypropyl methylcellulose (HPMC), cellulose fibers, and carrot minimal processing waste (CMPW)

\subsection{Optimized biocomposite}

Response surfaces built from models fitted to the mechanical attributes of the ternary biocomposites investigated by means of a mixture design are presented in Fig. 2. The regression coefficients are compiled in Table 4.

As elucidated in Fig. 2, higher CMPW levels led to poorer mechanical properties. On the other hand, larger amounts of the binding agent - HPMC - provided films with greater resistance, extensibility, and thus toughness. These findings are in agreement with those discussed in Section 3.2. Cellulose fibers, in turn, provided a pronounced stiffness to the biocomposites in which they were present. It is therefore possible to obtain biocomposites with different levels of mechanical performance by adjusting the FFF as to the proportions among their components. Because this study set out to develop a biocomposite comprising as much food processing waste as possible, but still featuring physical-mechanical properties that allow its commercial applicability as a packaging material, the formulation considered 
Table 4

Estimated coefficients for tensile strength $\left(\sigma_{\mathrm{T}}\right.$, in MPa), Young's modulus ( $E$, in $\mathrm{MPa})$, and elongation at break $\left(\varepsilon_{B}\right.$, in $\left.\%\right)$ of biocomposite films comprising different weight ratios of carrot minimal processing waste $\left(X_{C M P W}\right)$, cellulose fibers $\left(X_{C F}\right)$, and hydroxypropyl methylcellulose $\left(X_{H P M C}\right)$.

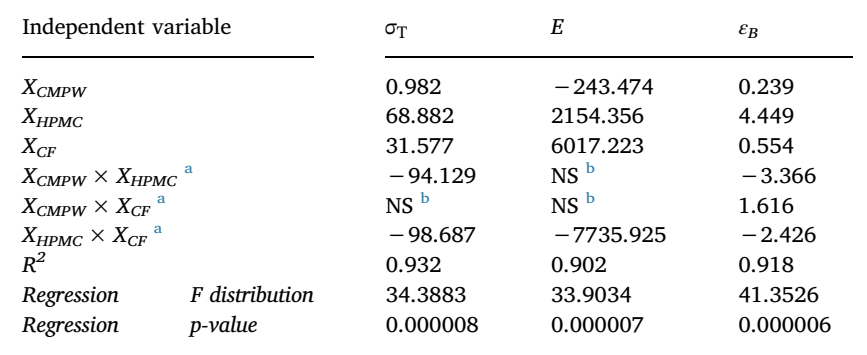

a $\times$ indicates the interaction among two variables.

b NS: non-significant.

Table 5

Respirometric assay. Chemical oxygen demand and $\mathrm{CO}_{2}$ production during aerobic biodegradation of starch powder, thermoplastic starch film (TPS), and optimized and scaled-up biocomposite.

\begin{tabular}{|c|c|c|c|c|}
\hline \multirow[t]{2}{*}{ Sample } & \multirow[t]{2}{*}{ Molecule ${ }^{a}$} & \multirow{2}{*}{$\begin{array}{l}\mathrm{DQO}^{\mathrm{a}} \\
\left(\mathrm{gg}^{-1}\right)\end{array}$} & \multicolumn{2}{|c|}{$\mathrm{CO}_{2}$ production $\left(\mathrm{mL} \mathrm{g}^{-1}\right)$} \\
\hline & & & $75 \mathrm{~d}^{\mathrm{b}}$ & Theoretical ${ }^{a}$ \\
\hline Starch & $\mathrm{C}_{10} \mathrm{H}_{15} \mathrm{O}_{8}$ & 1.2 & 30.8 & 42.6 \\
\hline TPS & $\mathrm{C}_{8} \mathrm{H}_{13} \mathrm{O}_{6}$ & 1.3 & 36.5 & 43.7 \\
\hline Biocomposite & $\mathrm{C}_{8} \mathrm{H}_{15} \mathrm{O}_{9}$ & 0.9 & 17.3 & 35.1 \\
\hline
\end{tabular}

a Theoretical values.

b Values obtained experimentally.

optimum would result in a tensile strength higher than those of PCL (4 MPa) and LDPE (8-10 MPa) and similar to those of EVOH (6-19 MPa) and HDPE ( $\geq 19 \mathrm{MPa}$ ); a Young's modulus similar to those of PS (2.8 GPa) and PVC (2.7-3.5 GPa) and higher than those of LDPE (150-340 MPa), PCL (386 MPa), and PVDC (200-600 MPa); and an elongation at break comparable to that of PS (2-3\%) (Bastarrachea et al., 2011; Li et al., 2011). These materials were taken as references because they have been widely used commercially as food packaging materials. The optimum formulation comprised $33 \mathrm{wt} \%$ of CMPW, $14 \mathrm{wt} . \%$ of HPMC, and $53 \mathrm{wt} . \%$ of cellulose fibers. Under these conditions, the minimal processing of each kilogram of fresh carrot would generate sufficient waste to produce $1.4 \mathrm{~kg}$ of biocomposite.

\subsection{Scaled-up biocomposite}

The production of the optimum biocomposite formulation was extended to the pilot scale through continuous casting. This approach allowed a faster water removal from FFF. In the bench casting process, the FFF was deposited over a substrate and detached from it only after $24 \mathrm{~h}$ of drying. In the continuous casting process, in contrast, the dried film was wound $30 \mathrm{~min}$ after depositing the FFF over the conveying substrate. The continuous approach under the aforementioned conditions allowed the production of $1.56 \mathrm{~m}^{2}$ of biocomposite per hour. By extrapolating this value to the 24 -h period required for bench casting to end up with dried films, $37.4 \mathrm{~m}^{2}$ of biocomposite film would be produced on a pilot scale. Considering bench casting, an area of at least $37.4 \mathrm{~m}^{2}$ would be required for such daily production, whereas in continuous casting the required area would be limited to the area occupied by the machine, i.e., $4.20 \mathrm{~m} \times 0.95 \mathrm{~m}=4 \mathrm{~m}^{2}$. Theoretically, to double the biocomposite production through continuous casting, it would be necessary to increase the width of the conveyor by $0.26 \mathrm{~m}$. That is, it would take $5.1 \mathrm{~m}^{2}$ for the daily production of $74.8 \mathrm{~m}^{2}$ under the conditions used here. To produce the same amount of biocomposite by bench casting, at least $74.8 \mathrm{~m}^{2}$ would be required. The values become

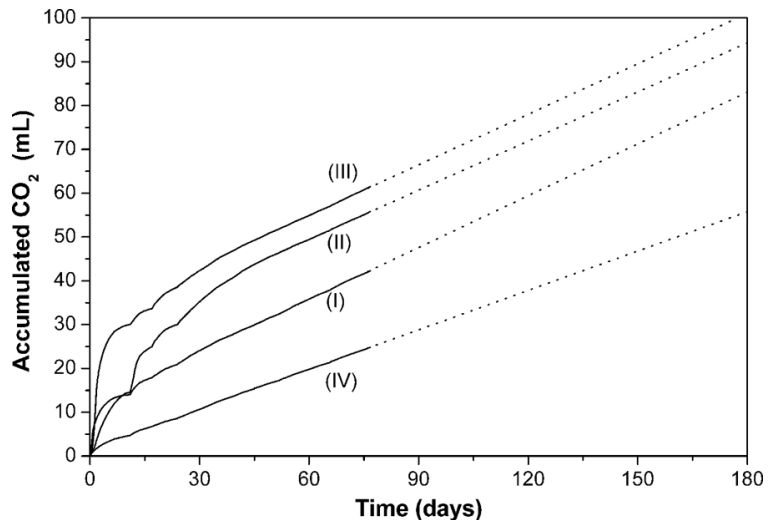

Fig. 3. Biodegradability of biocomposites. $\mathrm{CO}_{2}$ production during aerobic biodegradation in soil of (I) optimized and scaled-up biocomposites, (II) starch, (III) thermoplastic starch film, and (IV) control. Dotted lines indicate the estimated biodegradation.

increasingly divergent as the production volume is increased, corroborating the importance of continuous casting in ensuring the feasibility biocomposite production through solvent evaporation in an industrial scenario.

\subsection{Biodegradability of optimized and scaled-up biocomposites}

Accumulated carbon dioxide production resulting from aerobic biodegradation of the samples over 75 days is shown in Fig. 3. Calculated values and those obtained experimentally are shown in Table 5.

The results obtained in respirometric assays show that the three materials underwent aerobic biodegradation in soil, which is indicated by the higher mineralization - i.e., $\mathrm{CO}_{2}$ generation - in flasks that contained samples in relation to those containing only the inoculum (blank). Indeed, the biodegradability of starch and TPS have been widely reported (de Campos et al., 2013; Li et al., 2011), reason why these were used as references. Differences in respirometric profiles were already observed at the first days: the initial respiration rates of the biocomposite and the TPS films, indicated by the curve slopes, were higher than that of starch. Considering the biocomposite, this is attributed to the presence of low-molecular weight sugars - fructose, glucose, and sucrose, mainly (Alasalvar et al., 2001) - in CMPW. These sugars are more easily consumed by microorganisms than starch due to the macromolecular characteristic of the latter. The lower initial rate of starch when compared with TPS film results from the plasticizing action of glycerol molecules, which leads to increased accessibility of anhydroglucose units to the active sites of catalytic enzymes (Moura et al., 2011). Biodegradation is known to occurs preferentially in the amorphous domains and in chain ends, regions in which starch chains present greater flexibility and mobility than those located in their crystalline analogues (Li et al., 2011).

After 8 days, $\mathrm{CO}_{2}$ evolution of the biocomposite was equal to that of starch, which was always higher from the 11th day onwards. This observation can be attributed to the depletion of the aforementioned mono- and disaccharides - that are more easily consumed by the microorganisms than starch - as well as to the gradual breakdown of water-soluble starch granules due to the presence of the moist inoculum and the microbial enzymes.

Considering the theoretical $\mathrm{CO}_{2}$ production (Table 5), one may observe that the biocomposite reached $c a .50 \%$ of mineralization by the end of the test period. Taking into account the last 50 experimental points to adjust a linear equation $-\mathrm{CO}_{2}(\mathrm{~mL})=0.394 t+12.140$; $t=$ time (d); $R^{2}=0.9995$ - and extrapolating this behavior to 180 days as well as assuming that inoculum mineralization also behaves linearly $-\mathrm{CO}_{2}(\mathrm{~mL})=0.299 t+1.858 ; R^{2}=0.9999-$ it is possible to estimate that biocomposite mineralization would reach approximately $80 \%$. 


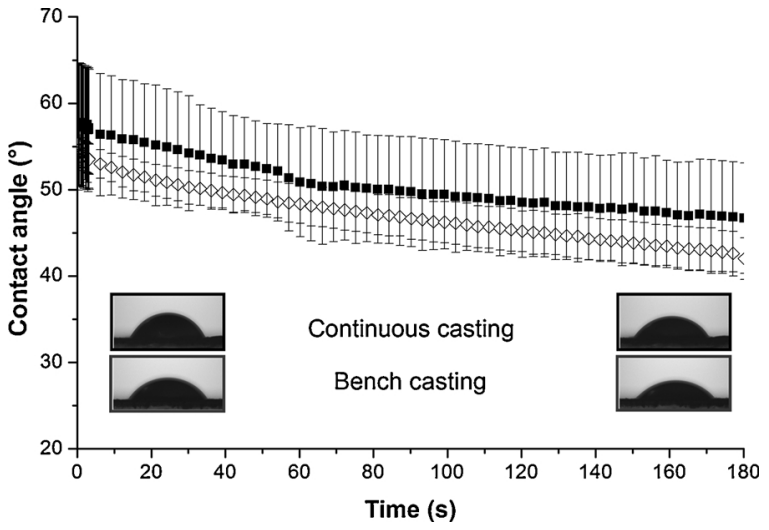

Fig. 4. Wettability of biocomposites. Contact angle between a water drop and biocomposite surfaces (left images: $0 \mathrm{~s}$, right: $180 \mathrm{~s}$ ) produced through continuous $(\square)$ or bench $(\diamond)$ casting.

However, the mineralization of the blank is expected to cease - i.e., switch from a linear behavior to a horizontal plateau - before that of the biocomposite because of the higher content of organic matter in the latter. In addition, $\mathrm{CO}_{2}$ is not the unique product of the aerobic biodegradation of a polymer. Indeed, most of the organic carbon is biodegraded into $\mathrm{CO}_{2}$, but some of it is incorporated into the soil as humus and biomass (ABNT, 1999) and another fraction remains as dissolved organic carbon (Li et al., 2011). Therefore, besides confirming that the biocomposite undergoes biodegradation in soil, it can be inferred that it is a biodegradable material according to ASTM D6400-12 (ASTM, 2012a).

\subsection{Physical-mechanical properties of non-scaled-up and scaled-up biocomposites}

Concerning the properties of biocomposites produced on laboratory and pilot scales, their wettability was determined to investigate a possible effect of moisture removal rate on moisture adsorption kinetics. Contact angle is plotted against time in Fig. 4.

Contact angle quantifies the affinity between the solid-state material and a particular liquid, higher values indicating lower affinities. In case of water, these measurements reveal the hydrophobicity of the material. There was a decreasing trend of contact angle as a function of contact time, suggesting that water was adsorbed by the biocomposites, regardless of the casting protocol. This is corroborated by the images inserted below the curves, which show an attenuation of the contact angle after $180 \mathrm{~s}$. Water adsorption and contact angle values lower than below $90^{\circ}$ are characteristic of predominantly wetting materials and are attributed to the hydrophilic compounds present in CMPW as well as to the high occurrence of polar groups in cellulose fibers and HPMC matrix (Otoni et al., 2018). The film-forming procedure, however, did not imply significant changes in the wettability profiles of biocomposites produced by bench and continuous casting.

The WVP values of the biocomposites (Table 6) are in line with their contact angles with water, confirming that scaling up the production of CMPW-based biocomposites did not alter their affinity to moisture.

This observation makes sense when one considers that the moisture adsorption is the very first stage of permeation process, being then followed by diffusion and desorption of the permeant molecules (Ferrer et al., 2017). Therefore, moisture adsorption and permeation do not limit the scale up of the biocomposites under the conditions studied here. The WVP values of the CMPW-based biocomposites herein reported are higher than those presented by most synthetic polymers, such as HDPE $\left(0.00083 \mathrm{~g} \mathrm{~mm} \mathrm{~m}^{-2} \mathrm{~h}^{-1} \mathrm{kPa}^{-1}\right)$, LDPE $\left(0.003 \mathrm{~g} \mathrm{~mm} \mathrm{~m}^{-2} \mathrm{~h}^{-1} \mathrm{kPa}^{-1}\right)$, and EVOH $\left(0.010 \mathrm{~g} \mathrm{~mm} \mathrm{~m}^{-2} \mathrm{~h}^{-1} \mathrm{kPa}^{-1}\right)$ (McHugh et al., 1996). However, these values can be considered low in the context of edible and/or biodegradable films based on fruits and
Table 6

Physical-mechanical properties of the biocomposites. Tensile strength $\left(\sigma_{\mathrm{T}}\right)$, Young's modulus $(E)$, elongation at break $\left(\varepsilon_{\mathrm{B}}\right)$, and water vapor permeability (WVP) of laboratory- and pilot-scale biocomposites.

\begin{tabular}{lll}
\hline Parameter & Bench casting & Continuous casting \\
\hline WVP $\left(\mathrm{g} \mathrm{mm} \mathrm{kPa}^{-1} \mathrm{~h}^{-1} \mathrm{~m}^{-2}\right)$ & $1.8 \pm 0.1^{\mathrm{a}}$ & $2.0 \pm 0.6^{\mathrm{a}}$ \\
$\sigma_{T}$ - parallel direction $(\mathrm{MPa})$ & $30 \pm 2^{\mathrm{b}}$ & $7 \pm 1^{\mathrm{a}}$ \\
$\sigma_{T}$ - transverse direction (MPa) & $27 \pm 4^{\mathrm{b}}$ & $5.7 \pm 0.9^{\mathrm{a}}$ \\
$E$ - parallel direction (GPa) & $2.0 \pm 0.2^{\mathrm{B}}$ & $1.6 \pm 0.2^{\mathrm{A}}$ \\
$E$ - transverse direction (GPa) & $2.0 \pm 0.2^{\mathrm{B}}$ & $1.2 \pm 0.2^{\mathrm{A}}$ \\
$\varepsilon_{B}$ - parallel direction (\%) & $2.8 \pm 0.4^{\mathrm{\beta}}$ & $0.6 \pm 0.1^{\alpha}$ \\
$\varepsilon_{B}$ - transverse direction (\%) & $2.3 \pm 0.7^{\mathrm{\beta}}$ & $0.6 \pm 0.1^{\mathrm{a}}$
\end{tabular}

${ }^{a b A B \alpha \beta}$ Within the same set of properties (separated by horizontal lines), different mean values \pm standard deviations $\left({ }^{*} \mathrm{P}<0.05\right)$ are followed by different letters.

vegetables (Otoni et al., 2017).

The mechanical properties of the optimized biocomposites produced by bench casting (Table 6) are suitable for packaging applications. The tensile strength, for instance, is comparable to typical values of HDPE (19-31 MPa), PS (higher than $31 \mathrm{MPa}$ ), and PP (higher than $27 \mathrm{MPa}$ ) and even higher than those of PCL, LDPE, and EVOH (ASTM, 2012b; Bastarrachea et al., 2011). When the film-forming methods are compared, however, it is clear that the scale up impaired the mechanical attributes. This mechanical depreciation is related to the formation of water vapor bubbles within the biocomposite structure (Fig. 5).

Even though the FFF were degassed under vacuum to produce films free of macroscopic air bubbles, accelerating water removal in continuous casting by drying films at temperatures above water boiling temperature provided enough energy to change the physical state of the water contained in the FFF. Some of the water vapor generated in this process may remain entrapped as bubbles within the material and act as macroscopic defects, causing premature failure upon mechanical requested. Finally, regardless of the film-forming method, the biocomposites behaved isotropically, since their mechanical properties in parallel and transverse directions to lamination did not differ $(* \mathrm{P}>0.05)$.

\section{Conclusions}

In summary, we herein report the production of biodegradable biocomposites based on the waste generated in carrot minimal processing and containing HPMC and cellulose fibers as binding and reinforcement agents, respectively. The properties of these materials can be tailored by adjusting the proportion among their components according to predicted mathematical models that fitted well experimental data, eliminating the need for further tests. Although CMPW impaired

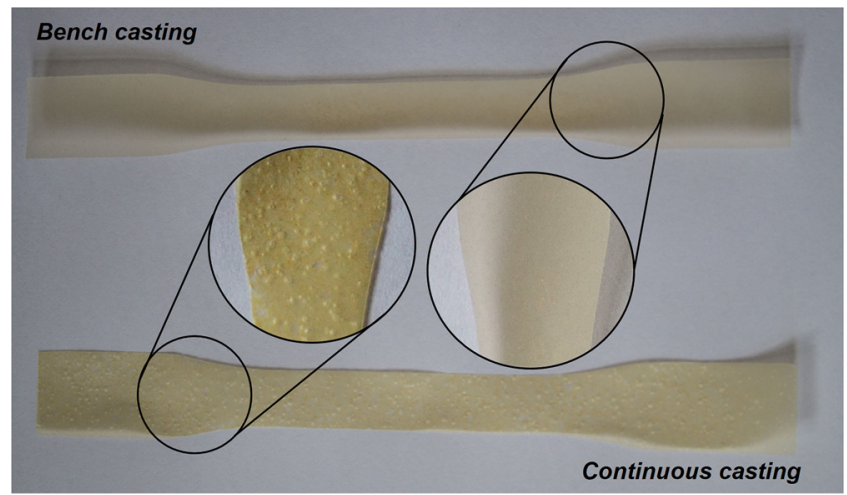

Fig. 5. Non-scaled-up and scaled-up biocomposites. Biocomposites based on carrot minimal processing waste produced on a laboratory (top) or a pilot scale (bottom). 
the mechanical performance of such materials, biocomposites featuring suitable mechanical properties for packaging applications were produced with $33 \mathrm{wt} . \%$ of carrot processing waste. Scaling up the production of such materials was shown to be feasible, but there may be mechanical depreciation depending on the processing parameters, requiring further studies on strategies to increase productivity while still maintaining physical-mechanical properties. Concerning scaled-up processing, is it suggested that future investigations exploit continuous casting variables such as feed rate, conveyor speed, wet layer thickness and wideness, infrared intensity, number of convective drying stages, rate of atmosphere renewal, and temperature gradient in order to pave the route for the industrial application of the herein produced biodegradable composite films.

\section{Funding}

This work was supported by the São Paulo Research Foundation (FAPESP) [grant numbers 2013/14366-7 and 2014/23098-9], National Council for Scientific and Technological Development (CNPq) [grant number 303796/2014-6], and Ministry of Science, Technology, and Innovation (MCTI/SISNANO) [award number 402287/2013-4].

\section{Acknowledgements}

Authors thank the financial support of FAPESP (grants \#2013/ 14366-7 and \#2014/23098-9), CNPq, SISNANO/MCTI, FINEP, and Embrapa AgroNano research network; the support by Henriette M. C. Azeredo and Marilia Oliveira (Embrapa CNPAT) and Milene M. Foschini, Gabrielle C. Pestana, and Karen A. F. Santos (Embrapa Instrumentação); and the kind donation of HPMC samples by The Dow Chemical Company.

\section{References}

ABNT NBR 14283, 1999. Resíduos em solos - Determinação da biodegradação pelo método respirométrico. Associação Brasileira de Normas Técnicas, Rio de Janeiro, Brazil.

ASTM D6400-12, 2012a. Standard Specification for Labeling of Plastics Designed to Be Aerobically Composted in Municipal or Industrial Facilities. ASTM International, West Conshohocken, PA. http://dx.doi.org/10.1520/D6400-12.

ASTM D5988-12, 2012b. Standard Test Method for Determining Aerobic Biodegradation of Plastic Materials in Soil. ASTM International, West Conshohocken, PA. http://dx. doi.org/10.1520/D5988-12.

ASTM D882-12, 2012c. Standard Test Method for Tensile Properties of Thin Plastic Sheeting. ASTM International, West Conshohocken, PA. http://dx.doi.org/10.1520/ D0882-12.

Alasalvar, C., Grigor, J.M., Zhang, D., Quantick, P.C., Shahidi, F., 2001. Comparison of volatiles, phenolics, sugars, antioxidant vitamins, and sensory quality of different colored carrot varieties. J. Agric. Food Chem. 49, 1410-1416.

Andrade, R.M.S., Ferreira, M.S.L., Goncalves, E.C.B.A., 2016. Development and characterization of edible films based on fruit and vegetable residues. J. Food Sci. 81, E412-E418.

Azeredo, H.M.C., Mattoso, L.H.C., Wood, D., Williams, T.G., Avena-Bustillos, R.J., McHugh, T.H., 2009. Nanocomposite edible films from mango puree reinforced with cellulose nanofibers. J. Food Sci. 74, N31-N35.

Azeredo, H.M.C., Miranda, K.W.E., Ribeiro, H.L., Rosa, M.F., Nascimento, D.M., 2012. Nanoreinforced alginate-acerola puree coatings on acerola fruits. J. Food Eng. 113, 505-510.

Azeredo, H.M.C., Rosa, M.F., Mattoso, L.H.C., 2017. Nanocellulose in bio-based food packaging applications. Ind. Crops Prod. 97, 664-671.

Azeredo, H.M.C., 2009. Nanocomposites for food packaging applications. Food Res. Int. $42,1240-1253$.

Bastarrachea, L., Dhawan, S., Sablani, S.S., 2011. Engineering properties of polymeric based antimicrobial films for food packaging: a review. Food Eng. Rev. 3, 79-93.
Bilbao-Sáinz, C., Avena-Bustillos, R.J., Wood, D.F., Williams, T.G., McHugh, T.H., 2010. Composite edible films based on hydroxypropyl methylcellulose reinforced with microcrystalline cellulose nanoparticles. J. Agric. Food Chem. 58, 3753-3760.

Bilbao-Sainz, C., Bras, J., Williams, T., Sénechal, T., Orts, W., 2011. HPMC reinforced with different cellulose nano-particles. Carbohydr. Polym. 86, 1549-1557.

de Campos, A., Tonoli, G.H.D., Marconcini, J.M., Mattoso, L.H.C., Klamczynski, A., Gregorski, K.S., Wood, D., Williams, T., Chiou, B.-S., Imam, S.H., 2013. TPS/PCL composite reinforced with treated sisal fibers: Property, biodegradation and waterabsorption. J. Polym. Environ. 21, 1-7.

de Moraes Crizel, T., Haas Costa, T.M., de Oliveira Rios, A., Hickmann Flôres, S., 2016. Valorization of food-grade industrial waste in the obtaining active biodegradable films for packaging. Ind. Crops Prod. 87, 218-228.

de Moura, M.R., Avena-Bustillos, R.J., McHugh, T.H., Wood, D.F., Otoni, C.G., Mattoso, L.H.C., 2011. Miniaturization of cellulose fibers and effect of addition on the mechanical and barrier properties of hydroxypropyl methylcellulose films. J. Food Eng. 104, 154-160.

Dogan, N., McHugh, T.H., 2007. Effects of microcrystalline cellulose on functional properties of hydroxy propyl methyl cellulose microcomposite films. J. Food Sci. 72, E016-E022.

Du, W.-X., Avena-Bustillos, R.J., Breksa III, A.P., McHugh, T.H., 2012. Effect of UV-B light and different cutting styles on antioxidant enhancement of commercial fresh-cut carrot products. Food Chem. 134, 1862-1869.

Ferrer, A., Pal, L., Hubbe, M., 2017. Nanocellulose in packaging: advances in barrier layer technologies. Ind. Crops Prod 95, 574-582.

George, J., Kumar, R., Sajeevkumar, V.A., Ramana, K.V., Rajamanickam, R., Abhishek, V., Nadanasabapathy, S., Siddaramaiah, 2014. Hybrid HPMC nanocomposites containing bacterial cellulose nanocrystals and silver nanoparticles. Carbohydr. Polym. 105, 285-292.

Graichen, F.H.M., Grigsby, W.J., Hill, S.J., Raymond, L.G., Sanglard, M., Smith, D.A., Thorlby, G.J., Torr, K.M., Warnes, J.M., 2017. Yes, we can make money out of lignin and other bio-based resources. Ind. Crops Prod. 106, 74-85.

Hiranvarachat, B., Devahastin, S., 2014. Enhancement of microwave-assisted extraction via intermittent radiation: extraction of carotenoids from carrot peels. J. Food Eng. $126,17-26$.

Hosseini, S.F., Rezaei, M., Zandi, M., Farahmandghavi, F., 2015. Bio-based composite edible films containing Origanum vulgare L. essential oil. Ind. Crops Prod. 67, 403-413.

Iahnke, A.O.S., Costa, T.M.H., Rios, A.O., Flôres, S.H., 2015. Residues of minimally processed carrot and gelatin capsules: potential materials for packaging films. Ind. Crops Prod. 76, 1071-1078.

Kanmani, P., Aravind, J., Kamaraj, M., Sureshbabu, P., Karthikeyan, S., 2017. Environmental applications of chitosan and cellulosic biopolymers: a comprehensive outlook. Bioresour. Technol. 242, 295-303.

Li, G., Sarazin, P., Orts, W.J., Imam, S.H., Favis, B.D., 2011. Biodegradation of thermoplastic starch and its blends with poly(lactic acid) and polyethylene: Influence of morphology. Macromol. Chem. Phys. 212, 1147-1154.

Lorevice, M.V., Moura, M.R., Aouada, F.A., Mattoso, L.H.C., 2012. Development of novel guava puree films containing chitosan nanoparticles. J. Nanosci. Nanotechnol. 12 2711-2717.

Lorevice, M.V., de Moura, M.R., Mattoso, L.H.C., 2014. Nanocomposite of papaya puree and chitosan nanoparticles for application in packaging. Quim. Nova 37, 931-936.

McHugh, T.H., Avena-Bustillos, R., Krochta, J.M., 1993. Hydrophilic edible films: Modified procedure for water vapor permeability and explanation of thickness effects. J. Food Sci. 58, 899-903.

McHugh, T.H., Huxsoll, C.C., Krochta, J.M., 1996. Permeability properties of fruit puree edible films. J. Food Sci. 61, 88-91.

Moretti, C.L., Mattoso, L.M., 2007. Processamento mínimo de minicenoura. In: Moretti, C.L. (Ed.), Manual de processamento mínimo de frutas e hortaliças. Embrapa Hortaliças, Brasília, Brazil.

Moura, I., Machado, A.V., Duarte, F.M., Nogueira, R., 2011. Biodegradability assessment of aliphatic polyesters-based blends using standard methods. J. Appl. Polym. Sci. 119, 3338-3346.

Otoni, C.G., Avena-Bustillos, R.J., Azeredo, H.M.C., Lorevice, M.V., Moura, M.R., Mattoso, L.H.C., McHugh, T.H., 2017. Recent advances on edible films based on fruits and vegetables-a review. Compr. Rev. Food Sci. Food Saf. 16, 1151-1169.

Otoni, C.G., Lorevice, M.V., Moura, M.R., Mattoso, L.H.C., 2018. On the effects of hydroxyl substitution degree and molecular weight on mechanical and water barrier properties of hydroxypropyl methylcellulose films. Carbohydr. Polym. 185, 105-111.

Silva, J.B.C., Vieira, J.V., Lana, M.M., 2008. Processing yield of the carrot cultivar Esplanada as affected by harvest time and planting density. Sci. Hort. 115, 218-222.

Souza, V.G.L., Fernando, A.L., Pires, J.R.A., Rodrigues, P.F., Lopes, A.A.S., Fernandes, F.M.B., 2017. Physical properties of chitosan films incorporated with natural antioxidants. Ind. Crops Prod. 107, 565-572. 